\title{
Complement Activation Contributes to Hypoxic-Ischemic Brain Injury in Neonatal Rats
}

\author{
Rita M. Cowell, ${ }^{1,3}$ Jennifer M. Plane, ${ }^{2}$ and Faye S. Silverstein ${ }^{1,2,3}$ \\ Departments of ${ }^{1}$ Neurology and ${ }^{2}$ Pediatrics, and ${ }^{3}$ Neuroscience Program, University of Michigan, Ann Arbor, Michigan 48109
}

\begin{abstract}
Conflicting data have emerged regarding the role of complement activation in the pathophysiology of cerebral ischemia. On the basis of considerable evidence implicating inflammatory mediators in the progression of neonatal brain injury, we evaluated the contribution of complement activation to cerebral hypoxic-ischemic (HI) injury in the neonatal rat. To elicit unilateral forebrain $\mathrm{HI}$ injury, 7-d-old rats underwent right carotid ligation followed by $1.5-2 \mathrm{hr}$ of exposure to $8 \%$ oxygen. Using immunoprecipitation and Western blot assays, we determined that $\mathrm{HI}$ induces local complement cascade activation as early as $8 \mathrm{hr}$ post-HI; there was an eightfold increase in the activation fragment inactivated $\mathrm{C} 3 \mathrm{~b}$ at $16 \mathrm{hr}$. With immunofluorescence assays and confocal microscopy, both C3 and C9 were localized to injured neurons 16 and $24 \mathrm{hr}$ post-HI. To investigate the contribution of systemic complement to brain injury, we administered the complementdepleting agent cobra venom factor $(\mathrm{CVF}) 24 \mathrm{hr}$ before $\mathrm{HI}$ lesioning and evaluated both acute $\mathrm{HI}$-induced complement deposition and the extent of resulting tissue injury $5 \mathrm{~d}$ after lesioning. CVF depleted both systemic and brain C3 by the time of surgery and reduced infarct size. Analysis of lesioned, CVF-treated animals demonstrated minimal neuronal C3 deposition but no reduction in C9 deposition. C3-immunoreactive microglia were identified in injured areas. These results indicate that complement activation contributes to $\mathrm{HI}$ injury in neonatal rat brain, systemic administration of CVF does not eliminate complement deposition within injured brain, and microglia may represent an important local source of $\mathrm{C} 3$ after acute brain injury.
\end{abstract}

Key words: microglia; endothelium; cobra venom factor; neonatal rat; stroke; C3

\section{Introduction}

Substantial evidence implicates complement activation in the pathogenesis of diverse acute and chronic CNS disorders (Morgan et al., 1997; Singhrao et al., 1999; D’Ambrosio et al., 2001). The complement cascade is the effector arm of the innate and humoral immune systems. Complement activation refers to the process of complement cascade initiation and execution, which results in the production of inflammatory mediators (C3a, C5a), the opsonization of cells with components [C3b, inactivated C3b (iC3b)] for recognition and phagocytosis by macrophages, and the formation of lethal membrane attack complexes (MAC) (C5b-9) on target membranes. The term "deposition" describes the fixation of complement to cell membranes resulting from local complement activation. Multiple activators of complement are present in injured tissue, including phosphatidylserine on apoptotic cells (Mevorach et al., 1998), mitochondria or naked DNA released from necrotic cells (Gewurz et al., 1993), and extracellular matrix molecules (Hindmarsh and Marks, 1998).

A role for complement in ischemia-reperfusion injury was first established by Hill and Ward (1971); they pretreated animals with the active C3b homolog cobra venom factor (CVF) to de-

Received July 7, 2003; revised Sept. 3, 2003; accepted Sept. 4, 2003.

This research was supported by American Heart Association Predoctoral Award $0110233 Z$ (R.M.C.) and National Institutes of Health Award NS35059 (F.S.S.). We thank B. Paul Morgan for providing the $\mathrm{C} 9$ antibody, Rory Marks for technical advice, and Haiyan Xu for technical assistance.

Correspondence should be addressed to Dr. Faye S. Silverstein, 8301 MSRB III, 1150 West Medical Center Drive, Ann Arbor, Ml 48109. E-mail: fsilvers@umich.edu.

Copyright $\odot 2003$ Society for Neuroscience $\quad$ 0270-6474/03/239459-10\$15.00/0 plete systemic complement and reported a marked reduction in myocardial ischemic damage and neutrophil infiltration. Subsequently, CVF-induced complement depletion has been used to examine the role of complement activation in many models of ischemia-reperfusion injury. In models of CNS ischemic injury, conflicting findings have emerged. CVF improved cerebral blood flow and behavioral outcome after transient forebrain ischemia (Vasthare et al., 1998) but did not confer neuroprotection in a rabbit thromboembolic stroke model (Lew et al., 1999). To date, the strongest evidence implicating complement activation in the pathogenesis of ischemia-reperfusion brain injury used an alternative approach to inhibit complement activation. Huang et al. (1999) found that treatment with a fusion protein consisting of soluble complement receptor 1 and Sialyl Lewis ${ }^{\mathrm{x}}$ reduced neutrophil accumulation and cerebral infarct volumes in a mouse model of transient forebrain ischemia.

There is growing recognition that inflammation contributes to the pathogenesis of neonatal brain injury (Barks and Silverstein, 2002). Clinical data linking complement activation with neonatal brain injury include evidence that $\mathrm{C} 3$ is depleted after neonatal asphyxia (Grether et al., 1999), and that serum C3a and C5a increase after fetal acidosis (Sonntag et al., 1998). Two previous studies have evaluated the role of complement in neonatal brain injury models; CVF treatment did not reduce injury in a neonatal rodent hypoxic-ischemic (HI) model (Lassiter et al., 2001), but administration of C9 exacerbated injury in a similar model (Imm et al., 2002). These discrepant findings prompted us to reexamine whether complement activation contributes to neo- 
natal brain damage in a well characterized model of HI brain injury in 7-d-old [postnatal day (P) 7] rats. We evaluated the time course and neuroanatomical localization of HI-induced complement activation and used CVF to investigate the sources of complement in acutely injured brain and the impact of systemic complement depletion on the extent of tissue damage. We demonstrate that complement is activated acutely in HI brain and that complement depletion reduces $\mathrm{HI}$-induced complement activation and injury.

\section{Materials and Methods}

Antibodies and reagents. Primary antibodies and reagents used for immunohistochemistry and fluorescence included mouse anti-neuronalspecific nuclear protein (NeuN) (neurons; Chemicon, Temecula, CA), FITC- or biotin-conjugated Isolectin $\mathrm{B}_{4}$ (endothelium and microglia; Sigma, St. Louis, MO), goat anti-rat C3 (ICN Pharmaceuticals, Aurora, $\mathrm{OH}$ ), rabbit anti-rat C9 (generously provided by B. P. Morgan, University of Wales College of Medicine, Cardiff, UK), rabbit anti-rat activated caspase 3 (Cell Signaling Technology, Beverly, MA), and 4',6'diamidino-2-phenylindole (DAPI) (Molecular Probes, Eugene, OR). Secondary antibodies included biotinylated horse anti-mouse IgG, horse anti-goat IgG, goat anti-rabbit IgG (Vector Laboratories, Burlingame, CA), CY-2-conjugated donkey anti-mouse IgG, CY-3 donkey anti-goat IgG, and CY-5 donkey anti-rabbit IgG (preabsorbed for rat serum proteins; Jackson ImmunoResearch, West Grove, PA).

Animal protocols. To elicit HI injury, unsexed P7 Sprague Dawley rats $(10-15 \mathrm{gm})$ underwent right carotid ligation under continuous anesthesia with isofluorane as described previously (Cowell et al., 2002). In brief, after recovery in a thermoregulated incubator $\left(1 \mathrm{hr} ; 37^{\circ} \mathrm{C}\right)$, animals were placed in warmed chambers (partly submerged in a $36.5^{\circ} \mathrm{C}$ water bath) and exposed to $8 \% \mathrm{O}_{2} / 92 \% \mathrm{~N}_{2}$ for 1.5 or $2 \mathrm{hr}$. After hypoxia, animals recovered in a warm incubator $\left(37^{\circ} \mathrm{C}\right)$ for $30 \mathrm{~min}$ and were returned to the mother. In this model, the duration of hypoxia influences the severity of tissue injury, and the threshold duration of hypoxia to elicit reproducible ipsilateral forebrain injury is between 1 and $1.5 \mathrm{hr}$. In the first set of experiments (evaluation of the HI-induced complement activation and deposition in brain), we used a lesioning protocol, which elicits severe tissue damage in the majority of animals $(2 \mathrm{hr} \mathrm{HI})$. For the experiments evaluating potential injury-modifying interventions, we used a lesioning protocol that would enable us to readily discern either neuroprotection or exacerbation of injury ( $1.5 \mathrm{hr} \mathrm{HI})$.

To generate positive control brain samples for complement assays, the proinflammatory agent Zymosan A (particulate component of yeast cell wall; Sigma) was stereotaxically infused over $<1 \mathrm{~min}$, as a bolus injection, into the right cortex of isofluorane-anesthetized $\mathrm{P} 7 \mathrm{rats}(0.5 \mu \mathrm{l} ; 10 \mathrm{mg} / \mathrm{ml}$ in sterile PBS; $1.5 \mathrm{~mm}$ posterior to Bregma; $2 \mathrm{~mm}$ lateral; $1 \mathrm{~mm}$ deep). C3 cleavage (see Results) was detected $8-48 \mathrm{hr}$ after injection. On the basis of the review of cresyl violet-stained sections and caspase 3 immunohistochemistry, it appeared that Zymosan infusion did not induce cell death, remote from injection site-related trauma. Although C3 immunostaining increased diffusely in the injected hemisphere, we found no cellular deposition of C3 or C9 (data not shown).

To investigate the influence of systemic complement depletion before HI lesioning, CVF (originally from cobra Naja naja kaouthia; Advanced Research Technologies, San Diego, CA) was administered by intraperitoneal injection. To assess the effects of CVF on serum and brain C3 at this age, unlesioned animals received injections of $0.1 \mathrm{M}$ PBS or CVF (500 $\mu \mathrm{g} / \mathrm{kg}$ in $0.1 \mathrm{M}$ PBS) on P6 and were killed on P7, P8, or P12 ( $n=6$ per group). To determine the influence of CVF administration on HIinduced C3 and C9 accumulation and deposition and tissue injury, animals were injected with PBS or CVF on P6, lesioned $24 \mathrm{hr}$ later on P7, and killed on P8 (for Western blot and immunohistochemistry; $n=13$ per group) or P12 (for histopathology; $n=16-17$ per group). In the neuroprotection experiment, we estimated the group sample size required to identify a $20 \%$ difference in outcome, on the basis of results from previous studies in this model $(\alpha=0.05 ; \beta=0.8 ; n=15$ per group; Instat; Graphpad, San Diego, CA). All animal use protocols were approved by The University of Michigan Committee on Use and Care of Animals.
Tissue collection. To obtain tissue homogenates for Western blot analysis, animals were deeply anesthetized with an overdose of chloral hydrate $(300 \mathrm{mg} / \mathrm{kg})$ at $4,8,16,24$, or $72 \mathrm{hr}$ after $\mathrm{HI}(n=3$ per group $)$ and perfused intracardially with ice-cold saline (to clear blood-borne complement). Brains were removed, divided into left and right hemispheres, and homogenized in PBS on ice (20 sec; maximum speed; Tissue Tearor; Biospec Products, Bartlesville, OK). Homogenates were centrifuged $(13,000 \mathrm{rpm} ; 30 \mathrm{~min})$, and supernatants were stored at $-70^{\circ} \mathrm{C}$. Protein content of the samples was determined using the $\mathrm{D}_{\mathrm{c}}$ protein assay kit (Bio-Rad, Hercules, CA) with BSA as a standard.

To obtain brain samples for immunohistochemistry and immunofluorescence assays, animals were anesthetized with chloral hydrate and perfused with PBS $(10 \mathrm{ml})$ and $4 \%$ paraformaldehyde in PBS $(10 \mathrm{ml}) 8$, 16,24 , or $72 \mathrm{hr}$ after $\mathrm{HI}$ ( $n=3-4$ per group). To determine the effects of CVF on brain C3 content, tissue was collected from animals $24-48 \mathrm{hr}$ after CVF or PBS injection. Brains were removed, postfixed overnight in $4 \%$ paraformaldehyde (in PBS) at $4^{\circ} \mathrm{C}$, cryoprotected in graded sucrose solutions, embedded in Tissue-Tek OCT (VWR Scientific, Batavia, IL), frozen, and stored at $-70^{\circ} \mathrm{C}$ (Ivacko et al., 1996). Coronal sections through the striatum and hippocampus were collected on gelatin-subbed slides. Slides were dried overnight and either used immediately or stored at $-70^{\circ} \mathrm{C}$.

For analysis of serum complement content and hemolytic activity, blood $(100-400 \mu \mathrm{l})$ was obtained from anesthetized animals immediately before perfusions by intracardiac puncture ( 22 gauge needle); samples were incubated at $37^{\circ} \mathrm{C}(30 \mathrm{~min})$, placed on ice $(30 \mathrm{~min})$, and centrifuged at $2500 \mathrm{rpm}$ at $4^{\circ} \mathrm{C}(10 \mathrm{~min})$. The serum was collected and frozen at $-70^{\circ} \mathrm{C}$.

Immunoprecipitation and Western blot analysis. For analysis of serum C3, samples were diluted in PBS and loading buffer, boiled $\left(100^{\circ} \mathrm{C} ; 10\right.$ $\mathrm{min}$ ), and loaded (5 $\mu \mathrm{g}$ per lane) on a $10 \%$ acrylamide-SDS gel. Proteins were transferred to a Protran nitrocellulose membrane (Schleicher \& Schuell, Keene, NH), and membranes were blocked in 5\% fish skin gelatin in Tris-buffered saline (TBS; $0.15 \mathrm{M} \mathrm{NaCl}, 0.02 \mathrm{M}$ Tris, $\mathrm{pH}$ 7.6) with $0.1 \%$ Tween $20(\mathrm{Tw})$ overnight at $4^{\circ} \mathrm{C}$. The goat anti-rat $\mathrm{C} 3$ antibody was applied to the membrane for $1.5 \mathrm{hr}$ at room temperature (3\% gelatin/ $0.02 \% \mathrm{Tw} / \mathrm{TBS})$. The membrane was washed ( $0.5 \% \mathrm{Tw} / \mathrm{TBS})$, incubated with peroxidase-labeled donkey anti-rabbit IgG (3\% gelatin/0.02\% Tw/ TBS), and washed again. The membrane was incubated with a chemiluminescent substrate (Pierce, Rockford, IL) and exposed to Kodak Biomax film (Kodak, Rochester, NY).

Although preliminary immunohistochemistry experiments revealed substantial C3 deposition in HI tissue, little C3 was detected in preliminary Western blot assays of brain tissue $(100 \mu \mathrm{g})$; thus, an immunoprecipitation protocol was developed. All incubations were performed at $4^{\circ} \mathrm{C}$ on a rotator. Samples $(100 \mu \mathrm{g})$ were added to $475 \mu \mathrm{l}$ of radioimmunoprecipitation assay (RIPA) buffer ( $150 \mathrm{~mm} \mathrm{NaCl}, 1 \%$ Triton X-100, $0.5 \% \mathrm{Na}$ deoxycholate, $0.1 \% \mathrm{SDS}, 50 \mathrm{~mm}$ Tris, $\mathrm{pH} 8.0$ ) and incubated with $1 \mu \mathrm{g}$ of goat anti-C3 antibody ( $2 \mathrm{hr}$ ). Protein G beads ( $40 \mu \mathrm{l} ; 1: 1 \mathrm{v} / \mathrm{v}$ in RIPA; Sigma) were added to the lysate-antibody preparation for $1 \mathrm{hr}$ and then spun down $\left(13,000 \mathrm{rpm} ; 5 \mathrm{~min} ; 4^{\circ} \mathrm{C}\right)$ and washed three times with cold RIPA (high $\mathrm{NaCl} ; 0.5 \mathrm{M}$ ) and once with RIPA (low NaCl; 0.15 M). The wash buffer was removed, and $25 \mu \mathrm{l}$ of $2 \times$ loading buffer was added. Samples were briefly vortexed and then boiled $\left(10 \mathrm{~min} ; 100^{\circ} \mathrm{C}\right)$. The beads were spun down ( $5 \mathrm{~min} ; 1000 \mathrm{rpm}$; room temperature), and the supernatant was loaded onto a 7.5 or $10 \%$ polyacrylamide gel for electrophoresis. Proteins were transferred to a nitrocellulose membrane, and C3 was detected as for serum (see above). Distinct bands were detected at $120(\alpha \mathrm{C} 3), 70\left(\mathrm{iC}_{3} \mathrm{~b}_{1}\right), 65(\beta \mathrm{C} 3)$, and $43 \mathrm{kDa}\left(\mathrm{iC}_{3} \mathrm{~b}_{2}\right)$ (SawantMane et al., 1996) in both serum and brain samples. Negative controls for immunoprecipitation included both zymosan-injected brain homogenates incubated with nonspecific goat IgG (instead of the C3 antibody) and samples in which no tissue was added to the immunoprecipitation reaction (C3 antibody alone). Ponceau S (Sigma) was used to stain membranes after transfer to verify the equal loading of protein or C3 antibody in each lane.

Western blots were performed to measure brain content of C9; tissue homogenate supernatants ( $1 \mu \mathrm{g}$ of protein) were electrophoresed on a $7.5 \%$ polyacrylamide gel and processed as described above with the rab- 
bit anti-rat C9 and goat-anti rabbit IgG antibodies. A single band was detected at $70 \mathrm{kDa}$; note that under the denaturing and reducing conditions of the Western blot procedure, sources of C 9 could have included free C9, soluble C5b-9, and membrane-bound MAC.

For quantitation of $\mathrm{C} 3$ and $\mathrm{C} 9$, the optical density (OD) of each band (arbitrary OD units; counts per square millimeter) was measured using the Molecular Analyst Imaging System (Bio-Rad). Values were expressed as fold increase in OD (right hemisphere/left hemisphere - 1), percentage of normal (compared on same film), or as arbitrary OD units. Several exposures of each film were taken to assure that the bands used for quantitation were not saturated (overexposed).

Immunohistochemistry and light microscopy. Immunohistochemistry and microscopy protocols have been reported previously (Cowell and Silverstein, 2003). In brief, antibodies were diluted in PBS with 5\% normal serum (same species as the host of the secondary antibody) and $0.3 \%$ Triton X-100. Sections were washed, blocked in 10\% serum, and incubated with the primary antibody overnight at $4^{\circ} \mathrm{C}$. Sections were washed, incubated with a biotinylated secondary antibody, rinsed with $0.3 \%$ $\mathrm{H}_{2} \mathrm{O}_{2}$ in methanol, and washed before incubation with the avidin-biotin conjugate (Vectastain ABC Elite kit; Vector Laboratories). Immunoreactivity was visualized with diaminobenzidine as the chromogen (Research Genetics, Huntsville, AL). Sections were either counterstained briefly with cresyl violet or directly dehydrated and coverslipped with Permount. For negative controls, primary antibodies were replaced with an equal concentration of species-matched nonspecific IgG. Light microscopy was used to evaluate the extent of neuronal injury and complement deposition. Representative images were captured using a SPOT camera attached to a Nikon (Tokyo, Japan) Microphot-SA with $4 \times, 10 \times, 20 \times$, and $40 \times$ objectives, and images were directly imported into Adobe Photoshop 5.5 (Adobe Systems, San Jose, CA) for the adjustment of brightness, contrast, and sharpness.

Immunofluorescence and confocal microscopy. After incubation with the primary antibodies (overnight at $4^{\circ} \mathrm{C}$ ), sections were washed, incubated with the appropriate secondary antibodies ( $2 \mathrm{hr}$; room temperature), washed, and coverslipped with aqueous antifade media (Molecular Probes). Immunofluorescence was visualized in triple-channel mode on a Nikon Diaphot 200 microscope equipped with a Noran confocal laserscanning imaging system (Noran Instruments, Middleton, WI) and Silicon Graphics (Mountain View, CA) Indy workstation. Data were collected from each channel sequentially, and barrier filters minimized channel leak-through (500/25 bandpass barrier filter in the FITC/CY2 range; 605/55 bandpass barrier filter in the Rhodamine/CY3 range). The images from two or three channels were merged, and the brightness and contrast were adjusted with Adobe Photoshop 5.5 (Adobe Systems).

Hemolytic assay. To confirm complement depletion in CVF-treated animals, the total serum hemolytic activity of animals injected with PBS $(n=4)$ or CVF $(n=5)$ was determined using a $\mathrm{CH}_{50}$ hemolytic assay (Kabat and Mayer, 1961). Animals were injected on P6, and serum was isolated on P7 from $0.1-0.4 \mathrm{ml}$ of blood from intracardiac aspiration before perfusion. Serial dilutions of serum $(1: 5,1: 10,1: 15,1: 20)$ were incubated with sensitized sheep erythrocytes (Advanced Research Technologies) for $30 \mathrm{~min}$, the reaction was stopped with cold PBS, and the absorbance of the supernatant was read at $415 \mathrm{~nm}$ in triplicate. For the controls, the erythrocytes were incubated with water (100\% lysis) or PBS alone ( $0 \%$ lysis; background). The $\mathrm{CH}_{50}$ value represents the reciprocal of the dilution required to lyse $50 \%$ of the erythrocytes.

Histopathology. Five days after surgery (P12), animals (injected with PBS or CVF on P6; $n=16-17$ per group) were decapitated, and brains were removed, frozen on dry ice, and sectioned on a cryostat $(20 \mu \mathrm{m})$ from anterior striatum to posterior hippocampus. Every fourth section was mounted on gelatin-subbed slides; every fourth collected section was scanned and imported into NIH Image 1.61 for analysis of remaining tissue volume. Values are reported as derived lesion volume (volume of tissue on left minus volume of tissue on right) or as the percent damage $([1-($ volume of tissue on right/volume of tissue on left $)] \cdot 100) \pm$ SEM.

Statistical analysis. Means and SEMs were determined for each data set. For analysis of complement-related assays, the Kruskal-Wallis test was used to evaluate group differences. A two-way ANOVA (factoring treatment and region) was used to determine the effect of CVF treatment on lesion volume. Post hoc analyses were applied to identify differences between specific data points. Statistical significance was set at $p<0.05$.

\section{Results}

We incorporated two experimental methods to document complement activation in hypoxic-ischemic neonatal brain: the identification of inactivated $\mathrm{C} 3 \mathrm{~b}$ (iC3b) and $\mathrm{C} 9$ in injured tissue by Western blot and the localization of complement components C3 and C9 to the membranes of injured cells with immunohistochemistry and immunofluorescence. All animals were perfused with saline before brain removal and processing to minimize contamination of the samples with blood-derived complement components.

$\mathrm{C} 3$ is an essential component of the C3 convertase, the enzyme complex responsible for complement cascade progression and amplification. With immunoprecipitation and Western blot analysis, we identified the two chains of native $\mathrm{C} 3(\alpha: 120 \mathrm{kDa}$ and $\beta: 65 \mathrm{kDa}$ ) and two $\mathrm{C} 3$ activation fragments (iC3b; $70 \mathrm{kDa}$ and $43 \mathrm{kDa}$ ) in $\mathrm{HI}$ brain (Fig. $1 \mathrm{~A}$ ). The heavy chain of goat IgG used to capture $\mathrm{C} 3$ was detected in all lanes $(50 \mathrm{kDa})$; this was the only band detectable in negative control lanes (lane 1, C3 antibody alone; lane 2, positive control tissue plus nonspecific goat IgG). Little $\alpha \mathrm{C} 3$ or $\beta \mathrm{C} 3$ was detectable in normal brain (Fig. $1 A$, lane 3). As a positive control for complement activation in brain parenchyma, the complement activator Zymosan A $(10 \mu \mathrm{g} / \mu \mathrm{l})$ was injected into the right cortex. Zymosan stimulated C3 production (increases in $\alpha \mathrm{C} 3$ and $\beta \mathrm{C} 3$ ) as well as complement activation (increase in $\mathrm{iC} 3 \mathrm{~b}$; both 70 and $43 \mathrm{kDa}$ fragments) (Fig. $1 A$, lane 4).

In a sample from the contralateral hemisphere $24 \mathrm{hr}$ after $2 \mathrm{hr}$ HI (Fig. 1A; lane 5, HI-L), the $70 \mathrm{kDa}$ iC3b band was evident but the $43 \mathrm{kDa}$ iC3b was faint, whereas in the right (ipsilateral) hemisphere, both iC3b bands were increased (Fig. $1 A$; lane 6 HI-R). The intensity of the $43 \mathrm{kDa}$ iC3b band was similar to that in the zymosan-injected tissue. The $43 \mathrm{kDa}$ band was selected for quantitative analysis, because it was the strongest band in zymosanexposed serum (positive control; data not shown). Figure $1 B$ summarizes results of quantitative analysis of the $43 \mathrm{kDa}$ iC $3 \mathrm{~b}$ band in samples obtained from animals 4, 8, 16, 24, and $72 \mathrm{hr}$ after $\mathrm{HI}(2 \mathrm{hr} \mathrm{HI})$. iC3b accumulation was highest at $16 \mathrm{hr}$ after HI (Fig. $1 B$ ) ( $n=3$ per group; $p=0.017$; Kruskal-Wallis test).

Tissue C9 content was analyzed by Western blot in the same samples. Figure $1 C$ shows a C9 Western blot of normal and $\mathrm{HI}$ brain; C9 was detectable in normal P8 brain, and increases were evident $24 \mathrm{hr}$ after $\mathrm{HI}$ in the right (Fig. $1 C$, R) hemispheres when compared with normal P8 (Fig. 1C, N) and left hemispheres (Fig. $1 C, \mathrm{~L})$. C9 content in the right hemisphere increased threefold over normal control levels between 8 and $24 \mathrm{hr}$ after HI (Fig. 1D) $(n=3$ per group; $p=0.02$; Kruskal-Wallis test). Slight increases in C9, as well as $\alpha \mathrm{C} 3$ and iC3b, were observed in the left hemisphere with respect to normal brain. Previous studies have documented a subtle but consistent proinflammatory response in the contralateral hemisphere (Cowell et al., 2002).

Immunohistochemistry assays enabled us to determine the neuroanatomic and cell-specific localization C3 and C9. Faint C3 and C9 immunoreactivity was consistently present in the extracellular matrix of the normal P7-P8 cortex (data not shown) and the left hemisphere of brains from animals $8 \mathrm{hr}$ after HI (Fig. $2 A-D)$. This distribution of diffuse C3 and C9 immunoreactivity was absent in normal adult rat brain (data not shown). In contrast, after HI, C3 and C9 were concentrated on cell bodies within injured areas. C3 and C9 were invariably localized to the same regions in each brain, but the time course of complement depo- 
sition varied among regions. The first regions in which complement deposition was observed included the medial habenula, dentate gyrus, thalamus, and CA1 region of the hippocampus $(8-48 \mathrm{hr})$. Changes were discerned later in the cortex and striatum (16-48 hr), and immunoreactivity peaked in the CA3 region of the hippocampus between 48 and $72 \mathrm{hr}$. The specificity of $\mathrm{C} 3$ and $\mathrm{C} 9$ immunostaining was confirmed by the concurrent evaluation of negative control sections. In sections from normal brains, there was no immunostaining in negative controls. In sections from HI brains, there was typically light, diffuse, nonspecific immunostaining in the lesion territory.

At $8 \mathrm{hr}$ after $\mathrm{HI}$, a pronounced change in nuclear morphology was seen throughout the ipsilateral hemisphere in sections counterstained with cresyl violet (Fig. 2, compare $A-D$ and $E-H$ ). Although nuclei in the left hemisphere were lightly stained, large, and ovoid, nuclei in the right hemisphere were intensely stained, condensed, and fragmented. C3 and C9 immunoreactivity was concentrated on ipsilateral cerebral endothelium, especially throughout the cortex (Fig. 2E, G); we could not distinguish luminal versus abluminal sites of complement deposition. C3 and C9 immunoreactivity was sometimes detected on cell bodies (Fig. 2 E, G, arrowheads). At $16 \mathrm{hr}$ (data not shown) and $24 \mathrm{hr}, \mathrm{C} 3$ and C9 immunostaining was observed on cells throughout the right cortex and hippocampus (Fig. $2 I-L$ ) as well as the habenula, striatum, and thalamus (data not shown). Complement immunoreactivity was detected on neuronal cell bodies and processes (Fig. $2 M-P$ ). By $72 \mathrm{hr}$, immunoreactivity declined in most regions (Fig. 2Q,S). Intense immunostaining remained only on pyramidal cells within the hippocampal CA3 subfield (Fig. $2 R, T$ ), on scattered cells with the morphology of phagocytic microglia (data not shown), and on cells in the left cortex where delayed cell death occurs (Cowell et al., 2002). At 120 hr after HI, C3 and C9 immunostaining declined further, and only a few faintly immunoreactive cells were seen (data not shown).

To determine the identity of C3- and C9-immunoreactive cells, we used triple-labeling immunofluorescence and confocal microscopy. C3 and C9 were localized to ipsilateral endothelium 8 and 16 hr after HI (data not shown) and injured neurons throughout the ipsilateral hemisphere from $8-72 \mathrm{hr}$ after HI. Figure 3 highlights the cell specificity of complement deposition $24 \mathrm{hr}$ after HI. An antibody raised against the neuronal protein $\mathrm{NeuN}$ was used to identify neurons; NeuN immunohistochemistry readily identifies areas of acute neuronal damage in this model (Cowell et al., 2002). In comparison with the normal NeuN-positive neurons in the left cortex (Fig. 3A), NeuNpositive neurons in the right cortex were smaller and sparsely distributed (Fig. 3D). In the left cortex, light C3 immunoreactivity was detectable in the extracellular matrix (Fig. $3 B$ ). In the right cortex, intense C3 immunoreactivity was located in areas of damaged neurons (Fig. 3E). C3 was concentrated on small injured neurons and absent from the normal-appearing neurons in the vicinity (Fig. 3D, box; 3G). Numerous cells in the right hemisphere were also immunoreactive for the activated fragment of caspase 3 (Fig. $3 F$ ), indicating that these cells were dying by apoptosis, as reported previously in this model (Han et al., 2000). C3 often colocalized with activated caspase 3 (Fig. $3 F$, box; $3 H$, bright purple).

The distribution of C9 immunoreactivity was similar to that of C3. There was faint C9 immunostaining in the extracellular matrix of the left cortex (Fig. 3J) but in the right cortex, $\mathrm{C} 9$ was concentrated on cells throughout the injured area (Fig. 3M). When visualized with the nuclear counterstain DAPI, the nuclei of C9-negative cells in the left cortex were large and ovoid (Fig. $3 \mathrm{~K}, \mathrm{O})$; in contrast, the nuclei of injured C9-positive cells on the right side were small and fragmented (Fig. $3 N, P$ ). The concentration of C9 on injured cells confirmed that the increases in $\mathrm{C} 9$ observed by Western blotting were attributable to, at least in part, the formation of MAC on neurons. Triple labeling with NeuN, C3, and C9 antibodies indicated that C3 and C9 were deposited on the same injured cells (data not shown).

To investigate the contribution of systemically derived C3 to complement deposition and injury, we administered CVF $24 \mathrm{hr}$ before HI lesioning to deplete systemic C3 and evaluated C3 and C9 deposition (at $24 \mathrm{hr}$ ) and tissue injury (at $5 \mathrm{~d}$ ). C3 Western blot assays of serum samples from normal animals demonstrated that $24-48 \mathrm{hr}$ after CVF injection, $\alpha \mathrm{C} 3(120 \mathrm{kDa})$ was eliminated (Fig. 4A,B); C3 content began to recover at approximately P12. This CVF injection protocol also eliminated serum hemolytic activity within $24 \mathrm{hr}\left[\mathrm{CH}_{50} \pm \mathrm{SEM}\right.$; PBS $(n=4)$ : $0.082 \pm 0.01$; 


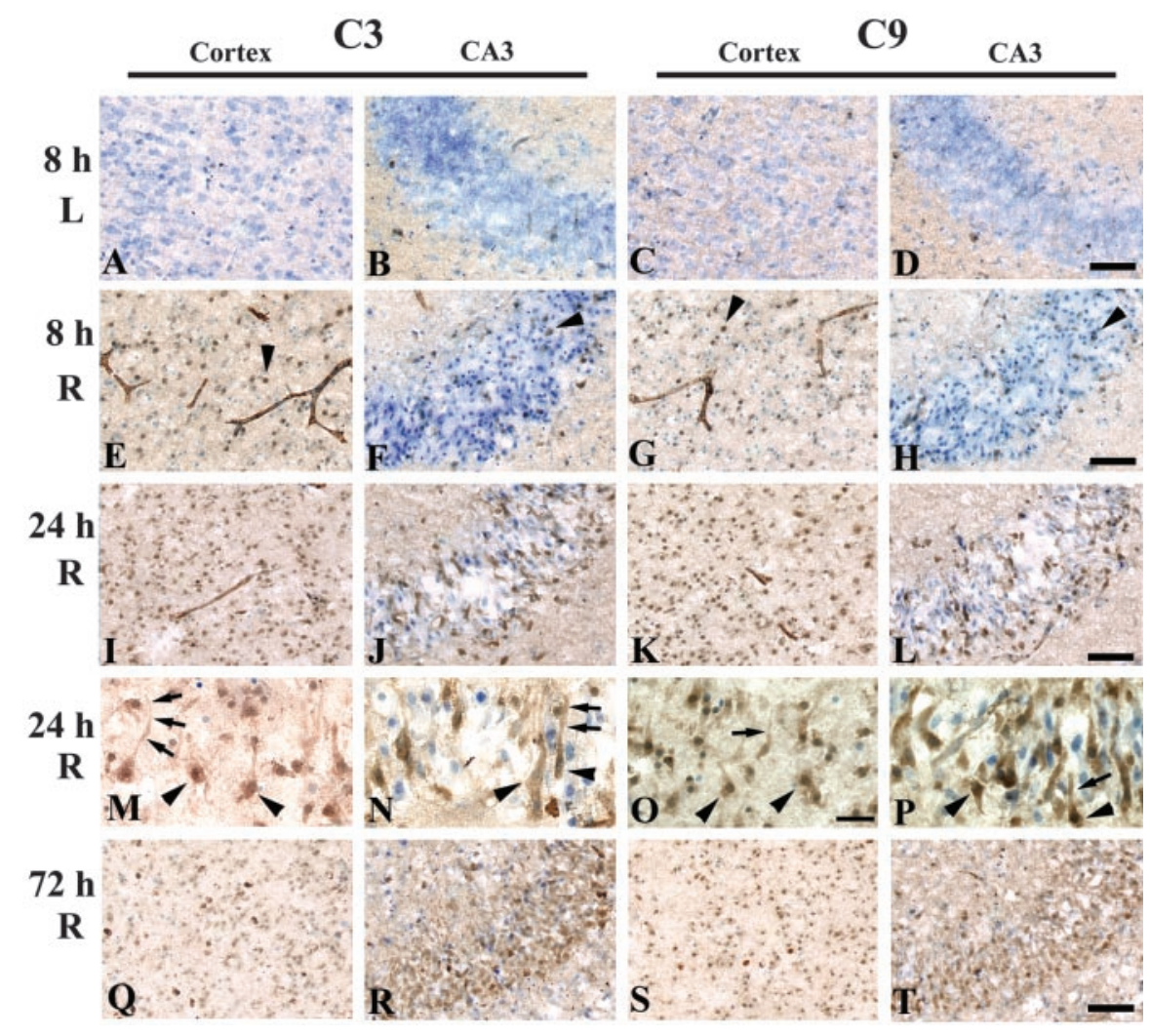

Figure 2. C 3 and $C 9$ are localized to areas of injury. Immunohistochemistry for $C 3$ and $C 9$ revealed changes in the distributions of $\mathrm{C} 3$ and $\mathrm{C} 9$ immunostaining $8-72 \mathrm{hr}$ after $\mathrm{HI}$ in the right cortex and $\mathrm{CA} 3$ subfield of the hippocampus. Serial sections (from 3-4 animals per time point) were analyzed for ( 3 and (9 immunoreactivity and counterstained with cresyl violet; images were collected from representative animals at 8,24 , and $72 \mathrm{hr}$ after $\mathrm{HI}$. At $8 \mathrm{hr}$, cells in the left hemisphere stain normally with cresyl violet $(A-D)$, whereas in the right hemisphere, many cells have condensed, darkly stained nuclei $(E-H)$. There is light $C 3$ and $C 9$ immunoreactivity (brown) in the extracellular matrix of the left cortex and hippocampus $(A-D)$. In contrast, throughout the right hemisphere, $C 3$ and $(9$ are concentrated on cerebral endothelium ( $E$ and $G$, respectively); few immunoreactive cell bodies are present ( $E--H$, arrowheads). In the right cortex and hippocampus at $24 \mathrm{hr}$, many cells with the location and morphology of neurons are immunoreactive for both $\mathrm{C} 3$ and $\mathrm{C} 9(I-L)$. Twenty-four hours after $\mathrm{HI}, \mathrm{C} 3$ and $\mathrm{C} 9$ immunoreactivity are concentrated on cell bodies (arrowheads) as well as neuronal processes (arrows) in the cortex $(M, 0)$ and hippocampus $(N, P)$. By $72 \mathrm{hr}, \mathrm{C} 3$ and $C 9$ immunostaining are less pronounced in the ipsilateral cortex $(Q, S)$. However, widespread $C 3$ and $C 9$ immunoreactivity are evident in the CA3 pyramidal cell layer $(R, T)$. Scale bars: $A-L, Q-T, 50 \mu \mathrm{m} ; M-P, 20 \mu \mathrm{m}$.

CVF $(n=5): 0.0034 \pm 0.003 ; p=0.01 ;$ Kruskal-Wallis test $]$. Analysis of C3 content in brain homogenates by Western blot demonstrated that CVF administration on P6 resulted in a substantial reduction in normal brain C3 content by P7 that lasted until P12 (Fig. 4C,D). In comparison with normal P7 brain (Fig. $4 E$ ), C3 immunostaining in the brains of CVF-treated animals was markedly diminished (Fig. $4 F$ ). CVF had no effect on serum or brain C9 (data not shown).

On the basis of the knowledge that complement activation can amplify inflammation, we hypothesized that systemic complement depletion would attenuate HI injury. However, given that the mode of action of CVF involves intravascular complement activation, we also recognized the possibility that CVF could augment ischemia-induced inflammation. Therefore, we evaluated the impact of CVF pretreatment using lesioning protocols that would enable us to discern both exacerbation and attenuation of injury. In preliminary experiments, CVF was administered on P6, animals underwent $1 \mathrm{hr}$ of $\mathrm{HI}$ on P7, and tissue injury was evaluated on P12 ( $n=16$ per group); there was minimal tissue damage in both groups (data not shown). In the next group of experiments, after P6 PBS or CVF administration, animals underwent $1.5 \mathrm{hr}$ HI. Comparison of derived lesion volume and percentage of damage values (Table 1) indicated that overall injury was reduced in the CVFtreated group $(n=16-17$ per group; $p<$ 0.02; two-way ANOVA; region $\times$ group). However, there was substantial variation in the extent of damage in CVF-treated animals, and in 4 of 16 CVF-treated animals, the extent of damage was greater than the group mean for PBS-treated animals.

To elucidate the mechanism of CVFmediated neuroprotection, we evaluated the influence of CVF administration on tissue complement activation by Western blot (Fig. 5) and deposition by immunohistochemistry (Fig. 6) at $24 \mathrm{hr}$ after HI. CVF pretreatment reduced the amount of iC $3 \mathrm{~b}$ accumulation in the brain after injury (Fig. 5A) [fold increase in $\mathrm{iC} 3 \mathrm{~b}$ in right hemisphere: $2.0 \pm 0.7$ (PBS) vs $0.1 \pm$ $0.4(\mathrm{CVF}) ; n=4$ per group; $p<0.01$ Kruskal-Wallis test]. In contrast, immunoassays for C9 in the same tissue samples revealed that CVF did not inhibit $\mathrm{HI}$ induced $\mathrm{C} 9$ accumulation in the right hemisphere (Figure 5C) [right hemisphere, percentage of normal: $184 \pm 19 \%$ (PBS) vs $163 \pm 13 \%$ (CVF); $n=4$ per group; $p=0.02$; Kruskal-Wallis test]. Note that the magnitude of iC3b accumulation in these samples was less than that observed for more severely lesioned brains (2 hr HI) (Fig. 1).

C3 and C9 immunohistochemistry assays of PBS-HI and CVF-HI brains confirmed these findings. There was substantial C3 deposition in PBS-HI brains $24 \mathrm{hr}$ after lesioning (compared with $\mathrm{C} 3$ in normal P8 brain) (Fig. 6A, C) and, in CVF-HI brains, the intensity of $\mathrm{C} 3$ immunoreactivity in the right hemisphere was reduced in comparison with PBS-HI animals (Fig. $6 D-F)$. Yet, there was a subtle increase in $\mathrm{C} 3$ immunoreactivity in the lesion territory compared with normal brain (Fig. 6, compare $D$ and $B$ ), and comparison with negative control sections confirmed that this immunoreactivity was specific. In contrast, C9 deposition was similar in PBS-HI and CVF-HI tissue (Fig. $6 G, H)$. Corresponding immunofluorescence assays analyzed with confocal microscopy confirmed that faint C3 immunoreactivity colocalized with $\mathrm{C} 9$ on condensed NeuN-positive neurons (data not shown). It is important to note that for all complementdepleted animals that underwent $\mathrm{HI}$ lesioning and were killed on P8, serum C3 content was evaluated by Western blot analysis to confirm that C3 was depleted at the time of the killing and HI did not induce the systemic production of native C3 (data not shown).

Because C3 deposition was still observed in complementdepleted animals, we evaluated potential sources of $\mathrm{C} 3$ in the CVF-HI brains. Figure $6, I-K$, shows examples of several C3immunoreactive cell types. In large round cells in the vicinity of dying neurons, C3 immunostaining was concentrated adjacent to the cell nucleus (juxtanuclear), suggestive of localization within the Golgi apparatus. These cells had the morphology of activated microglia and often exhibited cytoplasmic staining as well (Fig. 

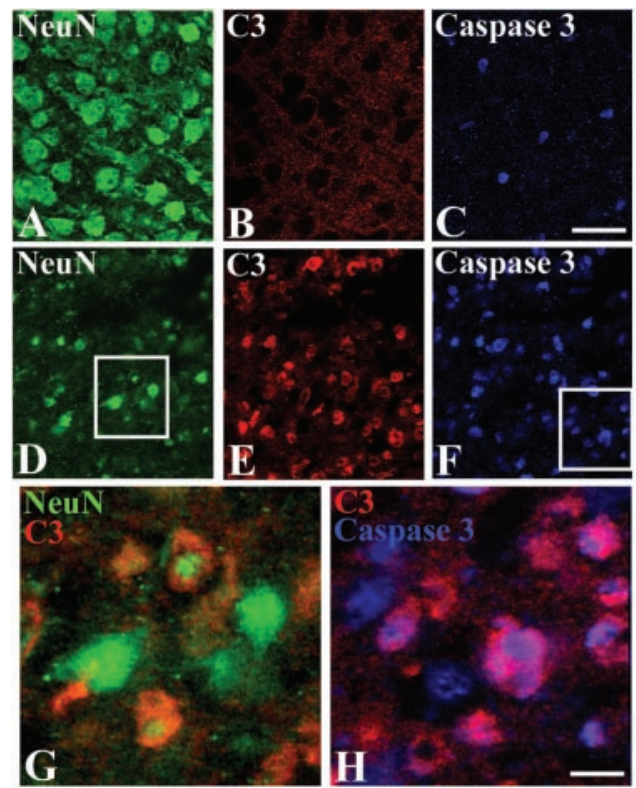
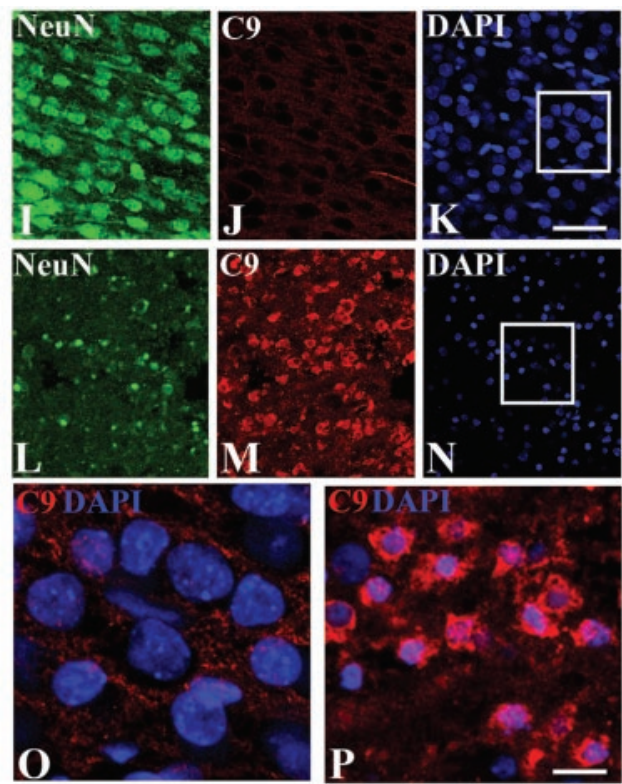

Figure 3. Localization of $\mathrm{C} 3$ and $\mathrm{C} 9$ immunoreactivity to injured neurons. Tissue was obtained $24 \mathrm{hr}$ after $\mathrm{HI}$, and brains were sectioned at $30 \mu \mathrm{m}$ for triple-labeling immunofluorescence and confocal microscopy (see Materials and Methods). $A$, NeuN immunostaining demonstrates the normal appearance and distribution of neurons in the left cortex. $B$, Light $C 3$ immunoreactivity is visible in the extracellular matrix. C, Few cells are immunoreactive for the activated fragment of caspase 3 . In the right (HI) cortex ( $D-F$ ), NeuN-positive neurons are markedly reduced in size and number (D). $E, F, C 3$ is concentrated on cell bodies in areas of shrunken neurons $(E)$ and activated caspase 3-positive cells $(F)$. When $D$ and $E$ are overlaid $(G)$, it is evident that $C 3$ immunoreactivity is concentrated on small injured neurons $(D$, box). When $E$ and $F$ are overlaid $(H), C 3$ colocalizes with activated caspase 3 (bright purple), indicating that $C 3$ is deposited on apoptotic neurons $(F$, box). The distribution of $(9$ immunoreactivity is similar to that of $(3$. In the left cortex ( $I-K)$, neuronal integrity is preserved $(I)$, and $(9$ is present in the extracellular matrix ( $J$ ). $K$, The nucleic acid stain DAPI demonstrates normal nuclear morphology. $L-N$, In the right $H$ l cortex, NeuN immunostaining reveals marked neuronal loss $(L)$, $C 9$ immunoreactivity is concentrated on cell bodies $(M)$, and DAPI staining shows that cell nuclei are condensed and fragmented $(M)$. C 9 is not localized to cell bodies in the uninjured cortex $(0 ; J, K$ overlay; $K$, box) but is concentrated on cells with a condensed nuclear morphology in the injured cortex ( $P ; M, N$, overlay; $N$, box). Scale bars: $A-F, I-N, 25 \mu \mathrm{m} ; G, H, O, P, 10 \mu \mathrm{m}$

6I); C3 colocalized with the monocyte-microglia marker Isolectin (data not shown). Other C3-immunoreactive cell types included endothelium (Fig. $6 \mathrm{~J}$ ), ependyma (Fig. $6 \mathrm{~K}$ ), and choroid plexus (data not shown).

\section{Discussion}

Our results demonstrate that neonatal HI brain injury activates the complement cascade, complement components are deposited on endothelial cells and dying neurons, and CVF administration reduces infarct size. Our study also illustrates the complexities and limitations inherent in using CVF treatment to delineate the role of complement activation in cerebral ischemiareperfusion injury. Despite depletion of C3 in serum and brain by CVF administration, there was evidence of residual HI-induced complement deposition in lesioned brain, which was likely attributable to local $\mathrm{C} 3$ production. In addition, although there were robust overall differences in lesion severity between PBS and CVF-treated animals, there was substantial variation in the extent of neuroprotection conferred by treatment.

We confirmed complement activation in injured brain tissue using both Western blot assays to detect and quantify the accumulation of $\mathrm{iC} 3 \mathrm{~b}$ and $\mathrm{C} 9$ and immunohistochemistry to localize complement components to injured cells. Initial Western blot assays of C3 in neonatal brain were unsuccessful. Generation of samples markedly enriched in activated complement by intracerebral injection of Zymosan enabled us to develop an immunoprecipitation protocol and optimize immunoblot assays of C3, in which native and inactivated C3 fragments could be distinguished. Because all samples were obtained from animals perfused with saline before tissue collection, systemic circulation sources of iC3b were minimized. In general, there was concordance between results of tissue homogenate and immunocyto- chemistry assays of complement in HI brain. To the best of our knowledge, this is the first report confirming the deposition of inactivated complement components in brain tissue using Western blot analysis.

With immunohistochemistry, endothelial localization of C3 and C9 immunoreactivity was evident as early as $8 \mathrm{hr}$ after HI. The contribution of the endothelium to the pathophysiology of HI injury in this neonatal stroke model is not well understood. Indirect evidence implicates endothelial mechanisms in the inflammatory response to ischemic brain injury. For example, in a recent study of the chemokine macrophage inflammatory protein (MIP)- $1 \alpha$ in this model, the earliest HI-induced increases in MIP- $1 \alpha$ expression were in monocytes within and closely associated with capillaries in the lesion territory $8 \mathrm{hr}$ after $\mathrm{HI}$ (Cowell et al., 2002), coinciding with the time point at which endothelial complement deposition was detected. Products of injuryinduced complement activation, such as C5a and $\mathrm{iC} 3 \mathrm{~b}$, may mediate chemokine production by binding to their respective receptors (C5aR or CR3) on monocytes-microglia. C5aR is expressed by microglia (Barnum, 1995), and C5a can enhance injuryinduced chemokine production in other injury models (Zhao et al., 2002). Complement activation products can also disrupt endothelial integrity and signaling (Ward, 1991; Saadi and Platt, 1995); the inhibition of acute complement activation on endothelial integrity and chemokine production may have contributed to the neuroprotective effects of CVF.

C3 and C9 immunoreactivity was consistently detected by 16 hr after HI on injured neurons. Confocal microscopy analysis demonstrated complement deposition on apoptotic neurons (on the basis of their morphology and activated caspase-3 expression) in the lesion territory. Both exposure of phosphatidylserine on 
A.

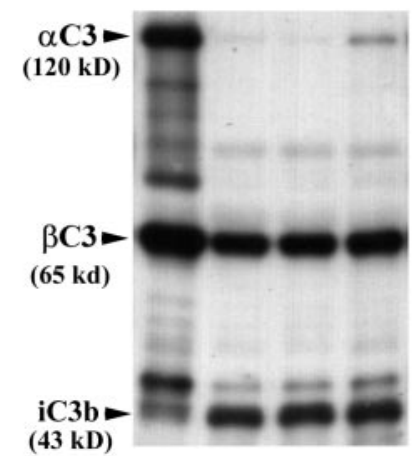

$\frac{\text { P7 }}{\text { PBS }} \frac{\text { P7 P8 P12 }}{\text { CVF }}$

C.
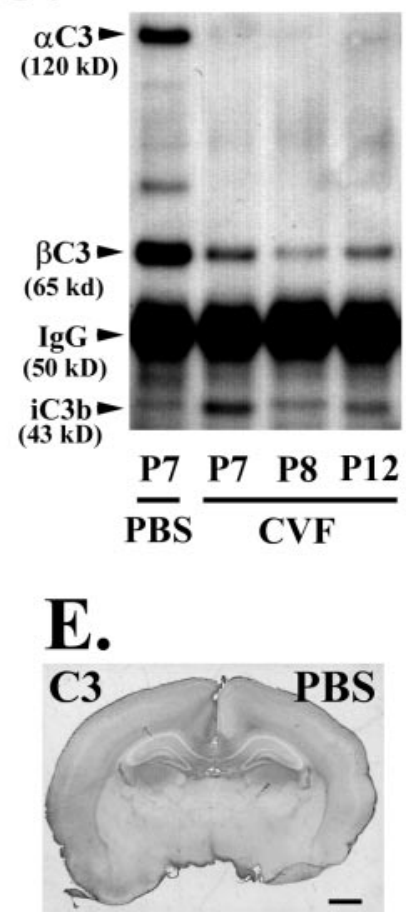

B.

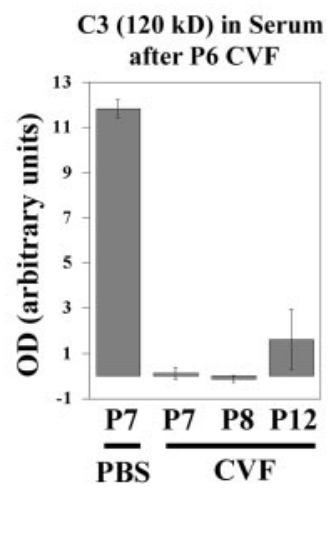

D.

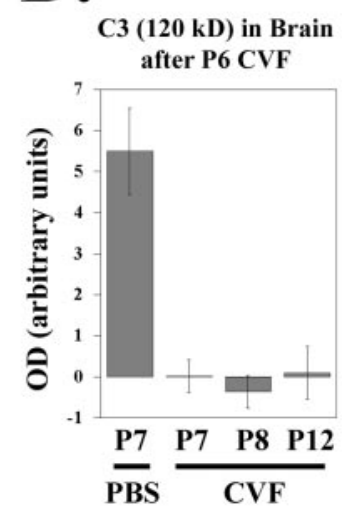

F.

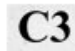

CVF

Figure 4. CVF depletes native C 3 in serum and brain. Normal P6 rats received intraperitoneal injections of vehicle (PBS) or CVF $(500 \mu \mathrm{g} / \mathrm{kg})$, and serum and brain samples were collected for C3 Western blot analysis (on $\mathrm{P} 7, \mathrm{P} 8$, and $\mathrm{P} 12 ; n=3$ per group) or immunohistochemistry (on P7). $A$, Comparison of serum C 3 in samples from PBS and CVF-injected animals demonstrates that $\alpha \mathrm{C} 3$ (120 kDa; target of C3 convertase-CVF) is absent in CVF-treated animals on P7 and P8, and a faint $\alpha$ C3 band is detected on P12.B, Quantitative analysis of serum $\alpha$ C3. Serum samples from P7 (P6 PBS) and P7, P8, and P12 (P6 CVF) animals ( $n=3$ per group) were included on the same gel and immunoblotted for C3. Band intensity expressed in arbitrary OD units $\pm \mathrm{SEM} \alpha \mathrm{C} 3$ is absent in P7 and P8 serum. C, C3 immunoprecipitation and Western blot of brain samples reveals that $\mathrm{P} 6$ CVF reduces $\alpha \mathrm{C} 3$ in $\mathrm{P} 7, \mathrm{P} 8$, and $\mathrm{P} 12$ brain. D, Quantitative analysis of $\alpha \mathrm{C} 3$ in brain. C3 was immunoprecipitated from P7 (P6 PBS) and P7, P8, and P12 (P6 CVF) brain, and samples ( $n=3$ per group) were assayed on the same gel. Band intensity is expressed in arbitrary $0 D$ units \pm SEM. P6 CVF eliminates $(3$ from $P 7, P 8$, and $P 12$ brain. $E, F$, Animals were injected with PBS $(E)$ or CVF $(F)$ on $\mathrm{P} 6$ and perfused on $\mathrm{P} 7$ for $\mathrm{C} 3$ immunohistochemistry. Representative sections at the level of the hippocampus revealed that in normal P7 brain, C3 immunoreactivity is distributed throughout the cortex, hippocampus, thalamus, and white matter; P6 CVF administration markedly reduces $\mathrm{C} 3$ immunoreactivity throughout the P7 brain. Scale bar: $E, F, 1 \mathrm{~mm}$. apoptotic cells and release of intracellular material from necrotic cells stimulate complement activation in vitro (Gewurz et al., 1993; Test and Mitsuyoshi, 1997; Mevorach et al., 1998). Therefore, it is likely that in the acutely injured neonatal brain, neuronal apoptosis may serve as a local stimulus for complement activation. Although neuronal morphological changes indicative of injury (e.g., nuclear shrinkage) generally preceded complement deposition, local complement activation could exacerbate ischemic injury by multiple mechanisms, including recruitment of inflammatory cells, disruption of the blood-brain barrier, and amplification of local tissue damage via MAC formation and release of intracellular contents. In this regard, it is intriguing to consider results of a recent study in adult rats (Xiong et al., 2003), which demonstrated that the sequential infusion of individual proteins of the membrane attack complex (C5b, C6, C7, C8, and C9) into the hippocampus induced seizures and cytotoxicity.

To determine whether complement activation influences $\mathrm{HI}$ lesion severity, systemic complement (C3 and C5) was depleted by administration of CVF $24 \mathrm{hr}$ before $\mathrm{HI}$, and the extent of tissue injury was assessed morphometrically $5 \mathrm{~d}$ later. Recently, investigators reported that CVF does not reduce HI brain injury in P7 (Imm et al., 2002) or P21 (Lassiter et al., 2001) rats. In those studies, outcome was analyzed 1-3 d after lesioning, time points at which the extent of tissue damage may be more difficult to evaluate in this neonatal stroke model. The extent of tissue damage and atrophy can be readily quantified at $5 \mathrm{~d}$ after lesioning (Liu et al., 1996), and the longer recovery period incorporated in this study may have facilitated identification of attenuation of injury. CVF initially depletes systemic complement by activating the complement cascade, and this process can transiently elicit proinflammatory signaling (Candinas et al., 1996; Cowell et al., 2001). We speculate that with a longer recovery period, the impact of this potential confounding factor was less pronounced. Note that a recent preliminary report (Ten et al., 2003) using genetically modified animals lacking the complement component $\mathrm{Clq}$ provides additional evidence that complement activation contributes to neonatal $\mathrm{HI}$ brain injury. In comparison with wild-type controls, P7 mice lacking C1q were resistant to HI brain injury.

To investigate the mechanisms contributing to CVFmediated neuroprotection, we evaluated the impact of CVF on complement activation and deposition in the brain. CVF administration markedly reduced injury-induced iC3b accumulation in tissue homogenates, indicating that the systemic circulation is a major source of $\mathrm{C} 3$ in the acutely injured brain. Yet, there was residual C3 immunoreactivity detected within several cell types in the lesion territory of CVF-treated HI animals. Of particular interest, microglia displayed immunoreactivity for $\mathrm{C} 3$ in a pattern that suggested production within the Golgi apparatus. Microglia may have generated sufficient amounts of C3 to initiate MAC formation, accounting for persistent injury-induced C9 deposition in CVF-treated animals. The observation of CVFinduced neuroprotection, despite C9 accumulation similar to that of controls, suggests that the neuroprotective effects of CVF may be mediated by a reduction in iC3b deposition or downstream activation products, rather than a reduction in MAC formation.

The findings of C3-immunoreactive microglia are congruent with results of previous studies in which mRNA transcripts encoding complement proteins were localized to microglia in animal models of transient global ischemia (Schafer et al., 2000) and cortical contusion (Bellander et al., 1996). Microglia have been implicated as a source of pathogenically important complement 
Table 1. Effect of CVF pretreatment on hypoxic-ischemic injury

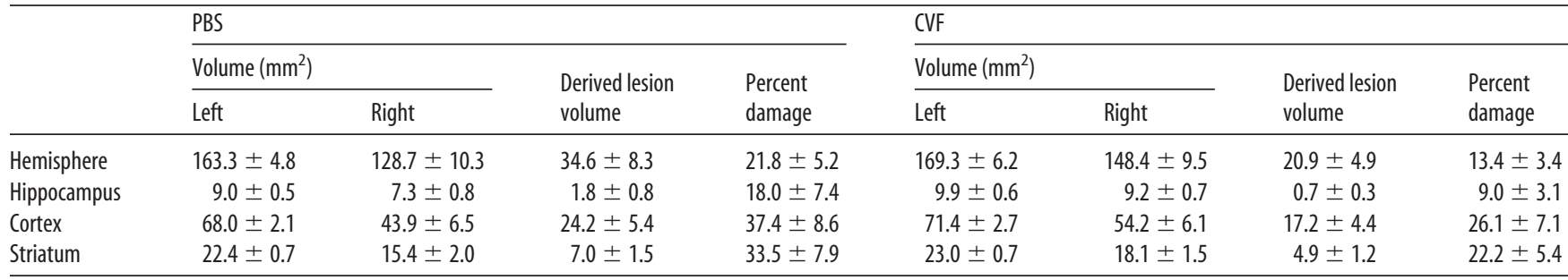

Animals received an injection of $\mathrm{PBS}$ or $\mathrm{CVF}$ on $\mathrm{P} 6$, underwent $\mathrm{HI}$ lesioning on $\mathrm{P7}$, and were killed on $\mathrm{P} 12$. Brains were removed, frozen, sectioned, and stained with cresyl violet. Regional tissue volumes ( $\mathrm{mm} \mathrm{m}^{2}$ ) were measured, and derived lesion volume and percent damage values were calculated as described in Materials and Methods. CVF pretreatment reduced tissue damage $(n=16-17$ per group; $p<0.02 ;$ two-way ANOVA).

production in several neurodegenerative disorders, including Alzheimer's disease (McGeer et al., 2000) and Huntington disease (Singhrao et al., 1999). Potential regulators of microglial C3 production in HI brain include C1q (Bajtay et al., 2000) and cytokines, such as interleukin- $1 \alpha$ and $-1 \beta$, tumor necrosis factor- $\alpha$, and TGF- $\beta$ (Hogasen et al., 1995; Mrak et al., 1995; Veerhuis et al., 1999). Other CNS cells that may produce C3

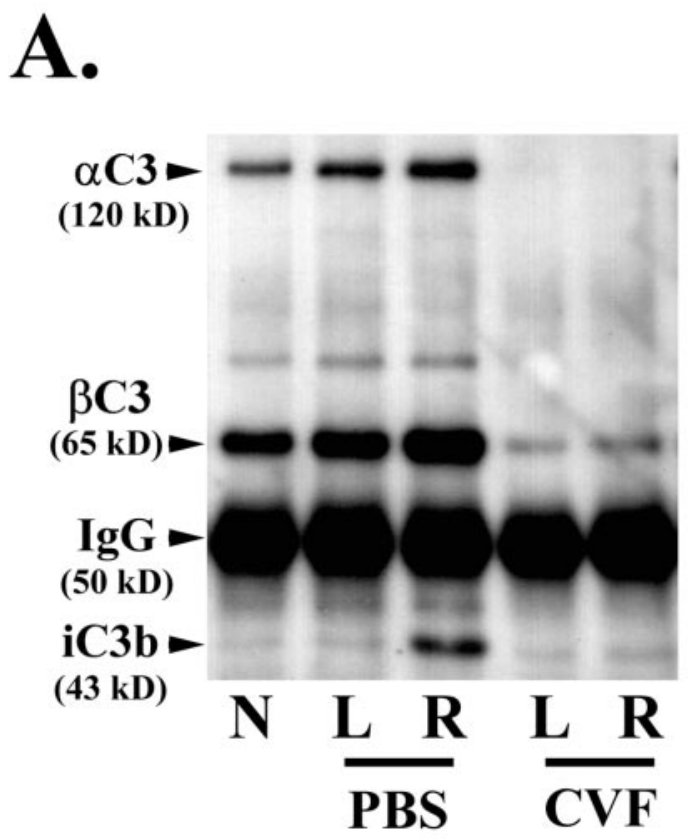

B.

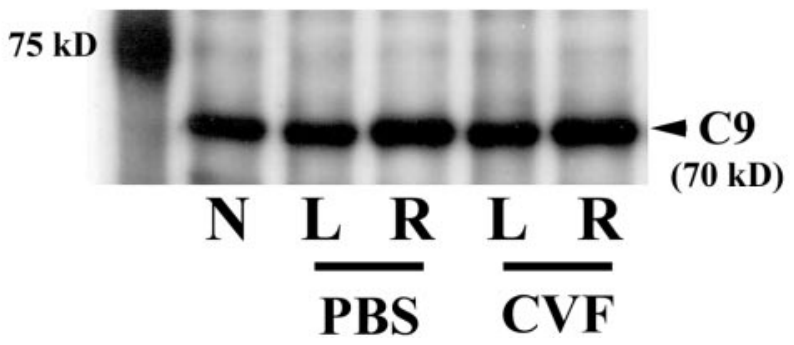

Figure 5. Systemic complement depletion reduces iC3b accumulation in the brain after $\mathrm{HI}$ but does not influence $\mathrm{C} 9$ accumulation. Animals were injected with PBS or CVF on P6 and underwent $\mathrm{HI}$ lesioning (1.5 hr) on P7; samples were obtained on P8 for Western blot analysis. $A$, In PBS-Hl animals, $\mathrm{i}(3 \mathrm{~b}(43 \mathrm{kd})$ increases in the right hemisphere (R) in comparison with the left hemisphere (L). Very little $\alpha \mathrm{C} 3(120 \mathrm{kDa})$ or i $3 \mathrm{~b}(43 \mathrm{kDa})$ is detectable in the $\mathrm{CVF}-\mathrm{HI}$ samples. $B, H$ induces $C 9$ accumulation in the right hemisphere in comparison with the normal (N) and left hemispheres. (9 accumulation was similar in PBS-HI and CVF-HI animals (see Results for quantitative analysis).

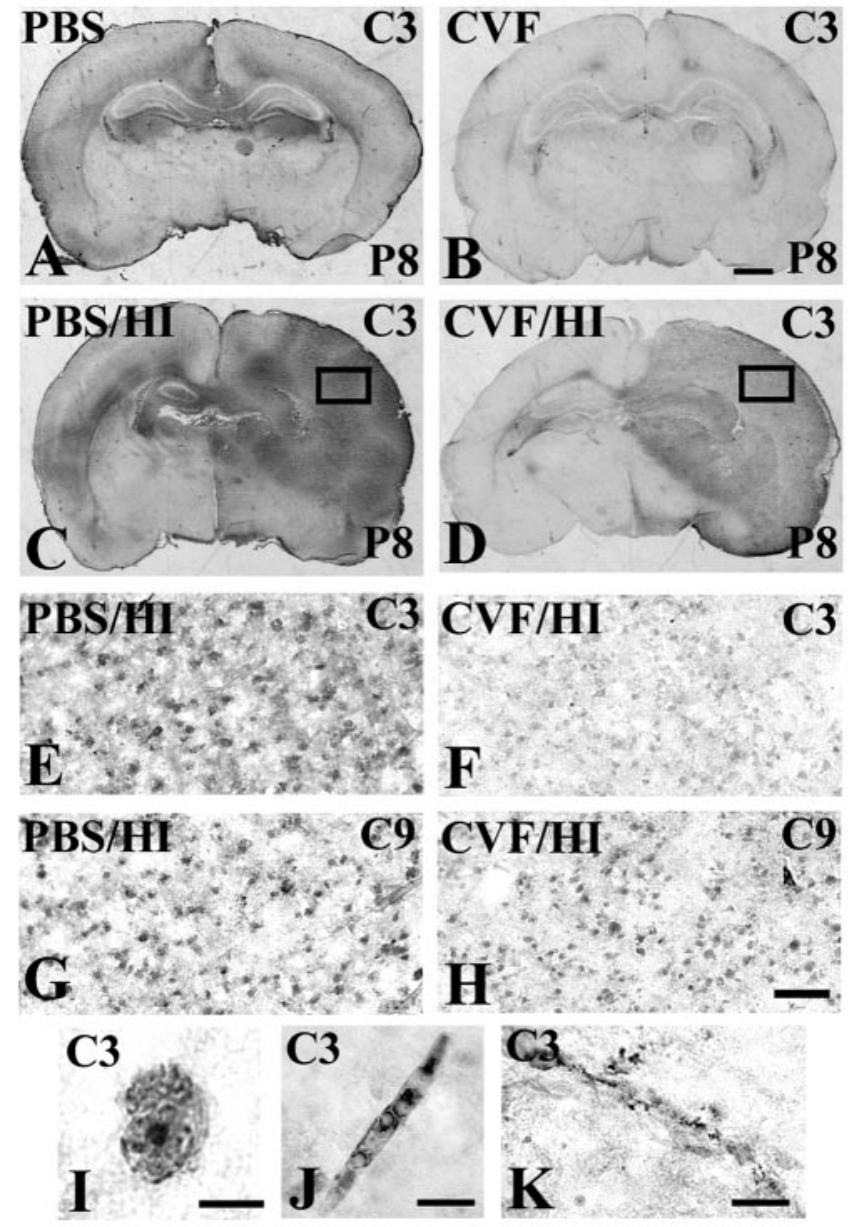

Figure 6. Systemic complement depletion does not eliminate complement deposition in the injured brain. $A, B$, Normal P6 animals were injected with either PBS or CVF and were perfused on P8. Representative sections at the level of the anterior hippocampus in normal P8 brain demonstrate $(3$ immunoreactivity throughout the cortex and concentrated along the ependymal cell layer in the hippocampus and thalamus $(A)$. CVF treatment on $\mathrm{P} 6$ reduces $(3$ immunoreactivity throughout the $\mathrm{P} 8$ brain $(B)$. $(-I$, After $\mathrm{PBS}$ or CVF injection on $\mathrm{P} 6, \mathrm{P} 7$ rats underwent right carotid ligation followed by $1.5 \mathrm{hr}$ hypoxia and were perfused on $\mathrm{P} 8$. Representative brain sections from PBS-HI ( $C$ ) and CVF-HI ( D) animals show that the intensity of injury-induced C3 immunoreactivity is reduced in CVF-HI animals in comparison with PBS-HI animals. When the right cortex of each animal is viewed at higher magnification, it is evident that $C 3$ immunoreactivity is concentrated on cell bodies and within the extracellular matrix in the PBS-HI animal $(E, C$, box) but is greatly reduced overall in the CVF-HI animal $(F, D$, box). Although reduced, $C 3$ immunoreactivity is not completely eliminated in the CVF-HI animals. Serial sections were processed for $\mathrm{C} 9$ immunohistochemistry; the intensity of $\mathrm{C} 9$ immunoreactivity did not differ significantly between PBS-HI ( $G$ ) and CVF-HI ( $H$ ) animals. In the CVF-HI brain, cell types other than neurons were $\mathrm{C} 3$ immunoreactive; cells with microglial morphology displayed $\mathrm{C} 3 \mathrm{immu}$ noreactivity throughout the cytoplasm and concentrated adjacent to the nucleus (I) (confirmed with cresyl violet counterstain; data not shown). Other (3-immunoreactive cells in the right hemisphere of the CVF-HI brain include endothelium ( () and ependyma ( $K$ ). Scale bars: $A-D, 1$ $\mathrm{mm} ; E-H, 50 \mu \mathrm{m} ; I, 10 \mu \mathrm{m} ; J, 25 \mu \mathrm{m} ; K, 20 \mu \mathrm{m}$. 
include ependyma, choroid plexus, endothelium, and astrocytes (Barnum et al., 1996; Nadeau and Rivest, 2001). In preliminary reverse transcriptase-PCR assays, we found increased C3 mRNA in the HI hemisphere as early as $16 \mathrm{hr}$ after HI (R.M.C., unpublished observations). Gasque et al. (2000) postulated that methods that modulate the local synthesis of complement regulators (i.e., glial- or neuron-targeted gene therapy) may effectively inhibit deleterious complement activation in the brain. In fact, astrocyte-targeted expression of the complement inhibitor sCrry inhibits demyelination in a rat model of multiple sclerosis (Davoust et al., 1999).

Although no C3 immunoreactivity was detected in the adult brain, C3 was consistently identified in P7 brain by both immunohistochemistry and Western blot analysis. Systemic CVF administration substantially depleted C3 from the P7 brain, supporting the idea that brain $\mathrm{C} 3$ is primarily derived from the systemic circulation. This interpretation is strengthened by the observation that, in comparison to the serum from CVF-depleted animals (Fig. 5A), the brain samples from these animals have little $\beta C 3$ (Fig. $5 C$ ). Thus, the presence of native $\mathrm{C} 3$ molecule in the CNS was reduced by CVF administration. Native C3 is a large molecule $(\sim 185 \mathrm{kDa})$ and may not passively diffuse across the intact blood-brain barrier (BBB). However, numerous transport mechanisms unique to the neonatal BBB (Saunders et al., 1999) could be responsible for shuttling $\mathrm{C} 3$ from the circulation into the CNS. In addition, microglia in younger rats (P3) are intensely immunoreactive for C3 (R.M.C., unpublished observation), suggesting that these cells may be an additional source of C3 in the developing brain. Both the systemic circulation and intrinsic CNS cells may provide the developing brain with complement for innate defense against invading organisms (Gasque et al., 2000) and for rapid responses to injury.

There is growing recognition that inflammatory mediators can exert beneficial as well as detrimental effects during the recovery period after acute brain injury (Mason et al., 2001). Although a preponderance of data suggests that complement activation exacerbates neurodegeneration, C5a may also exert neuroprotective effects (Mukherjee and Pasinetti, 2001). In addition, because $\mathrm{iC} 3 \mathrm{~b}$ increases the efficiency of phagocytosis by binding to complement receptor CR3 (Mac-1; CD11b) (Takizawa et al., 1996), complement inhibition could reduce removal of cell debris, thereby disrupting intrinsic repair mechanisms. Future studies will focus on delineating the sites and times at which complement inhibition can most effectively minimize amplification of tissue damage and enhance recovery after neonatal HI brain injury.

\section{References}

Bajtay Z, Jozsi M, Banki Z, Thiel S, Thielens N, Erdei A (2000) Mannanbinding lectin and $\mathrm{Clq}$ bind to distinct structures and exert differential effects on macrophages. Eur J Immunol 30:1706-1713.

Barks JDE, Silverstein FS (2002) Inflammation and neonatal brain injury. In: Birth asphyxia and the brain (Donn SM, Sinha SK, Chiswick ML, eds), pp 71-87. Armonk, NY: Futura.

Barnum SR (1995) Complement biosynthesis in the central nervous system. Crit Rev Oral Biol Med 6:132-146.

Barnum SR, Jones JL, Muller-Ladner U, Samimi A, Campbell IL (1996) Chronic complement C3 gene expression in the CNS of transgenic mice with astrocyte-targeted interleukin-6 expression. Glia 18:107-117.

Bellander BM, von Holst H, Fredman P, Svensson M (1996) Activation of the complement cascade and increase of clusterin in the brain following a cortical contusion in the adult rat. J Neurosurg 85:468-475.

Candinas D, Lesnikoski BA, Robson SC, Miyatake T, Scesney SM, Marsh Jr HC, Ryan US, Dalmasso AP, Hancock WW, Bach FH (1996) Effect of repetitive high-dose treatment with soluble complement receptor type 1 and cobra venom factor on discordant xenograft survival. Transplantation 62:336-342.

Cowell RM, Silverstein FS (2003) Developmental changes in the expression of chemokine receptor CCR1 in the rat cerebellum. J Comp Neurol 457:7-23.

Cowell RM, Xu H, Silverstein FS (2001) Identification of mechanisms that account for lack of neuroprotection with cobra venom factor (CVF)induced complement depletion in a neonatal rat stroke model. Soc Neurosci Abstr 27:864.

Cowell RM, Xu H, Galasso JM, Silverstein FS (2002) Hypoxic-ischemic injury induces macrophage inflammatory protein-1alpha expression in immature rat brain. Stroke 33:795-801.

D'Ambrosio AL, Pinsky DJ, Connolly ES (2001) The role of the complement cascade in ischemia/reperfusion injury: implications for neuroprotection. Mol Med 7:367-382.

Davoust N, Nataf S, Reiman R, Holers MV, Campbell IL, Barnum SR (1999) Central nervous system-targeted expression of the complement inhibitor sCrry prevents experimental allergic encephalomyelitis. J Immunol 163:6551-6556.

Gasque P, Dean YD, McGreal EP, VanBeek J, Morgan BP (2000) Complement components of the innate immune system in health and disease in the CNS. Immunopharmacology 49:171-186.

Gewurz H, Ying SC, Jiang H, Lint TF (1993) Nonimmune activation of the classical complement pathway. Behring Inst Mitt 93:138-147.

Grether JK, Nelson KB, Dambrosia JM, Phillips TM (1999) Interferons and cerebral palsy. J Pediatr 134:324-332.

Han BH, D'Costa A, Back SA, Parsadanian M, Patel S, Shah AR, Gidday JM, Srinivasan A, Deshmukh M, Holtzman DM (2000) BDNF blocks caspase-3 activation in neonatal hypoxia-ischemia. Neurobiol Dis $7: 38-53$.

Hill JH, Ward PA (1971) The phlogistic role of C3 leukotactic fragments in myocardial infarcts of rats. J Exp Med 133:885-900.

Hindmarsh EJ, Marks RM (1998) Complement activation occurs on subendothelial extracellular matrix in vitro and is initiated by retraction or removal of overlying endothelial cells. J Immunol 160:6128-6136.

Hogasen AK, Hestdal K, Hogasen K, Abrahamsen TG (1995) Transforming growth factor beta modulates $\mathrm{C} 3$ and factor B biosynthesis and complement receptor 3 expression in cultured human monocytes. J Leukoc Biol 57:287-296.

Huang J, Kim LJ, Mealey R, Marsh Jr HC, Zhang Y, Tenner AJ, Connolly Jr ES, Pinsky DJ (1999) Neuronal protection in stroke by an sLex-glycosylated complement inhibitory protein. Science 285:595-599.

Imm MD, Feldhoff PW, Feldhoff RC, Lassiter HA (2002) The administration of complement component $\mathrm{C} 9$ augments post-ischemic cerebral infarction volume in neonatal rats. Neurosci Lett 325:175-178.

Ivacko JA, Sun R, Silverstein FS (1996) Hypoxic-ischemic brain injury induces an acute microglial reaction in perinatal rats. Pediatr Res 39:39-47.

Kabat EA, Mayer MM (1961) Experimental immunochemistry, Ed 2. Springfield, IL: Thomas.

Lassiter HA, Feldhoff RC, Dabhia N, Parker Jr JC, Feldhoff PW (2001) Complement inhibition does not reduce post-hypoxic-ischemic cerebral injury in 21-day-old rats. Neurosci Lett 302:37-40.

Lew SM, Gross CE, Bednar MM, Russell SJ, Fuller SP, Ellenberger CL, Howard D (1999) Complement depletion does not reduce brain injury in a rabbit model of thromboembolic stroke. Brain Res Bull 48:325-331.

Liu XH, Eun BL, Silverstein FS, Barks JD (1996) The platelet-activating factor antagonist BN 52021 attenuates hypoxic-ischemic brain injury in the immature rat. Pediatr Res 40:797-803.

Mason JL, Suzuki K, Chaplin DD, Matsushima GK (2001) Interleukin1beta promotes repair of the CNS. J Neurosci 21:7046-7052.

McGeer PL, McGeer EG, Yasojima K (2000) Alzheimer disease and neuroinflammation. J Neural Transm Suppl 59:53-57.

Mevorach D, Mascarenhas JO, Gershov D, Elkon KB (1998) Complementdependent clearance of apoptotic cells by human macrophages. J Exp Med 188:2313-2320.

Morgan BP, Gasque P, Singhrao S, Piddlesden SJ (1997) The role of complement in disorders of the nervous system. Immunopharmacology $38: 43-50$.

Mrak RE, Sheng JG, Griffin WS (1995) Glial cytokines in Alzheimer's disease: review and pathogenic implications. Hum Pathol 26:816-823.

Mukherjee P, Pasinetti GM (2001) Complement anaphylatoxin C5a neuro- 
protects through mitogen-activated protein kinase-dependent inhibition of caspase 3. J Neurochem 77:43-49.

Nadeau S, Rivest S (2001) The complement system is an integrated part of the natural innate immune response in the brain. Faseb J 15:1410-1412.

Saadi S, Platt JL (1995) Transient perturbation of endothelial integrity induced by natural antibodies and complement. J Exp Med 181:21-31.

Saunders NR, Habgood MD, Dziegielewska KM (1999) Barrier mechanisms in the brain, II. Immature brain. Clin Exp Pharmacol Physiol 26:85-91.

Sawant-Mane S, Piddlesden SJ, Morgan BP, Holers VM, Koski CL (1996) CD59 homologue regulates complement-dependent cytolysis of rat Schwann cells. J Neuroimmunol 69:63-71.

Schafer MK, Schwaeble WJ, Post C, Salvati P, Calabresi M, Sim RB, Petry F, Loos M, Weihe E (2000) Complement C1q is dramatically up-regulated in brain microglia in response to transient global cerebral ischemia. J Immunol 164:5446-5452.

Singhrao SK, Neal JW, Morgan BP, Gasque P (1999) Increased complement biosynthesis by microglia and complement activation on neurons in Huntington's disease. Exp Neurol 159:362-376.

Sonntag J, Wagner MH, Strauss E, Obladen M (1998) Complement and contact activation in term neonates after fetal acidosis. Arch Dis Child Fetal Neonatal Ed 78:F125-F128.

Takizawa F, Tsuji S, Nagasawa S (1996) Enhancement of macrophagephagocytosis upon iC3b deposition on apoptotic cells. FEBS Lett 397:269-272.
Ten VS, Mazer SP, Minamoto K, Fedaru MA, Ratner V, Botto M, Pinsky D, (2003) Genetic deficiency of the complement component Clq protects neonatal mice against hypoxic-ischemic encephalopathy. Pediatr Res 53:541A.

Test ST, Mitsuyoshi J (1997) Activation of the alternative pathway of complement by calcium-loaded erythrocytes resulting from loss of membrane phospholipid asymmetry. J Lab Clin Med 130:169-182.

Vasthare US, Barone FC, Sarau HM, Rosenwasser RH, DiMartino M, Young WF, Tuma RF (1998) Complement depletion improves neurological function in cerebral ischemia. Brain Res Bull 45:413-419.

Veerhuis R, Janssen I, De Groot CJ, Van Muiswinkel FL, Hack CE, Eikelenboom P (1999) Cytokines associated with amyloid plaques in Alzheimer's disease brain stimulate human glial and neuronal cell cultures to secrete early complement proteins, but not C1-inhibitor. Exp Neurol 160:289-299.

Ward PA (1991) Mechanisms of endothelial cell killing by $\mathrm{H} 2 \mathrm{O} 2$ or products of activated neutrophils. Am J Med 91:89S-94S.

Xiong ZQ, Qian W, Suzuki K, McNamara JO (2003) Formation of complement membrane attack complex in mammalian cerebral cortex evokes seizures and neurodegeneration. J Neurosci 23:955-960.

Zhao H, Montalto MC, Pfeiffer KJ, Hao L, Stahl GL (2002) Murine model of gastrointestinal ischemia associated with complement-dependent injury. J Appl Physiol 93:338-345. 